\title{
Nitrergic Pathway Is the Major Mechanism for the Effect of DA-9701 on the Rat Gastric Fundus Relaxation
}

\author{
Yang Won Min, ${ }^{1}$ Eun-ju Ko, ${ }^{2}$ Ji Yeon Lee, ${ }^{2}$ Byung-Hoon Min, ${ }^{1}$ Jun Haeng Lee, ${ }^{1}$ Jae J Kim ${ }^{1}$ and Poong-Lyul Rhee ${ }^{1 *}$ \\ ${ }^{1}$ Department of Medicine and ${ }^{2}$ Biomedical Research Institute, Samsung Medical Center, Sungkyunkwan University School of Medicine, Seoul, \\ Korea
}

\section{Background/Aims}

DA-9701 significantly improved gastric accommodation by increasing the postprandial gastric volume. In this study, we investigated how DA-9701 affects the rat gastric fundus relaxation.

\section{Methods}

Gastric fundus muscle strips (9 longitudinal and 7 circular muscles) were obtained from rats. Electrical field stimulation (EFS) was performed at various frequencies $(1,5,10$ and $20 \mathrm{~Hz})$ and train durations $(1,5,10$ and 20 seconds) to select optimal condition for experiments. Isometric force measurements were performed in response to EFS. Peak and nadir were observed during the first 1 minute after initiation of EFS in control state and after sequential addition of atropine (1 $\mu \mathrm{M})$, DA-9701 (0.5, 5, 25 and $50 \mu \mathrm{g}), \mathrm{N}$-nitro-L-arginine $(\mathrm{L}-\mathrm{NNA}, 100 \mu \mathrm{M}), \mathrm{MRS} 2500(1 \mu \mathrm{M})$ and tetrodotoxin $(\mathrm{TTX}, 1 \mu \mathrm{M})$ to the organ bath.

\section{Results}

The optimal frequency and duration of EFS to evoke nerve-mediated relaxation was determined as $5 \mathrm{~Hz}$ for 10 seconds. Addition of L-NNA in the presence of atropine and DA-9701 $(50 \mu \mathrm{g})$ decreased nadir by inhibiting relaxation from $-0.054 \pm$ $0.021 \mathrm{~g}$ to $-0.022 \pm 0.015 \mathrm{~g}(P=0.026)$ in longitudinal muscles. However, subsequent application of MRS2500 in the presence of atropine, DA-9701 $(50 \mu \mathrm{g})$ and L-NNA did not affect nadir. In circular muscles, subsequent addition of L-NNA and MRS2500 in the presence of atropine and DA-9701 $(50 \mu \mathrm{g})$ did not show significant change of nadir.

\section{Conclusions}

Our data suggest that the effect of DA-9701 on the rat gastric fundus relaxation is mainly mediated by nitrergic rather than purinergic pathway.

(J Neurogastroenterol Motil 2014;20:318-325)

\section{Key Words}

DA-9701; Gastric fundus; Rats; Relaxation

Received: September 30, 2013 Revised: February 28, 2014 Accepted: March 12, 2014

(c) This is an Open Access article distributed under the terms of the Creative Commons Attribution Non-Commercial License (http://creativecommons. org/licenses/by-nc/3.0) which permits unrestricted non-commercial use, distribution, and reproduction in any medium, provided the original work is properly cited.

*Correspondence: Poong-Lyul Rhee, MD, PhD

Department of Medicine, Samsung Medical Center, Sungkyunkwan University School of Medicine, 81 Irwon-ro, Gangnam-gu, Seoul 135-710, Korea

Tel: +82-2-3410-3409, Fax: +82-2-3410-6983, E-mail: plrhee@skku.edu

Financial support: None.

Conflicts of interest: None.

Author contributions: Yang Won Min contributed to data analysis and interpretation, and drafted the manuscript; Eun-ju Ko and Ji Yeon Lee performed laboratory experiments; Byung-Hoon Min, Jun Haeng Lee and Jae J Kim performed critical revision of the manuscript; Poong-Lyul Rhee designed and coordinated the study, contributed to data interpretation, and edited the manuscript.

ORCID: Yang Won Min, http://orcid.org/0000-0001-7471-1305; Jae J Kim, http://orcid.org/0000-0002-0226-1330; Poong-Lyul Rhee, http://orcid.org/0000-0003-0495-5296. 


\section{Introduction}

Functional dyspepsia (FD) is a disorder characterized by the presence of chronic or recurrent symptoms of upper abdominal pain or discomfort in the absence of any known specific structural cause. ${ }^{1}$ Several pathophysiologic mechanisms have been suggested to underlie dyspeptic symptoms. These include delayed gastric emptying, impaired gastric accommodation to a meal, hypersensitivity to gastric distention, Helicobacter pylori infection, altered response to duodenal lipids or acid, abnormal duodenojejunal motility or central nervous system dysfunction. ${ }^{2}$ Delayed gastric emptying associated with the symptoms of postprandial fullness, nausea and vomiting, has been reported in approximately $30 \%$ of patients with FD. ${ }^{3,4}$ Impaired gastric accommodation associated with early satiety was present in $40 \%$ of patients with FD. ${ }^{5,6}$

DA-9701 is a newly-formulated prokinetic agent obtained from extracts of Pharbitis Semen and Corydalis Tuber. These plants have been used in Oriental traditional medicine for the treatment of gastrointestinal (GI) maladies. Pharbitis Semen, the seed of Pharbitis nil Choisy, has been used as a folk medicine for its analgesic effects on abdominal disorders. Corydalis Tuber, the root of Corydalis yahusuo W.T. $\mathrm{W}_{\mathrm{ANG}}$ (Papaveraceae), has been used as a folk medicine for its analgesic and anti-ulcer effects. Previous animal studies showed the effects of DA-9701 on GI function. ${ }^{7-9}$ DA-9701 increased gastric volume in a dose-dependent manner and improved gastric accommodation, which is an important pathophysiological mechanism associated with functional dyspepsia by increasing the postprandial gastric volume. ${ }^{9}$

Several animal studies have demonstrated that gastric accommodation in the fundus is a complex phenomenon induced by multiple neurotransmitters including nitric oxide (NO), adenosine triphosphate (ATP) and vasoactive intestinal polypeptide (VIP). ${ }^{10,11}$ In this study, we investigated the main mechanism of the effect of DA-9701 on the gastric fundus relaxation using rats.

\section{Materials and Methods}

\section{Animals}

For this study, Sprague-Dawley rats of male sex (250-300 g) were used. Gastric fundus smooth muscle strips (9 longitudinal muscles and 7 circular muscles) were obtained from 12 rats. This study was reviewed and approved by the Institutional Animal
Care and Use Committee of Samsung Biomedical Research Institute. Samsung Biomedical Research Institute is an Association for Assessment and Accreditation of Laboratory Animal Care International accredited facility and abide by the Institute of Laboratory Animal Resources guide.

\section{Organ Chamber Experiments}

Experiments were performed in vitro one time for each muscle strip from rat gastric fundus, recording the mechanical activity as changes in isometric force. Mechanical experiments were performed by using standard organ bath techniques. Gastric muscle strips were prepared by pinning the tissues to the base of a Sylgard silicone elastomer (Dow Corning, Midland, MI, USA) dish. The mucosa was removed by sharp dissection. After the mucosa was removed, thin strips of tissues were cut by use of parallel scalpel blades mounted on a scalpel handle. The final strips cut parallel to the circular and longitudinal muscle fibers measured $2 \times 10 \mathrm{~mm}$. The muscle strips were isolated and attached to a fixed mount and to a Fort 10 isometric strain gauge (UC3-GOULD Instruments, Paris, France; FT03-GRASS, Warwick, RI, USA). The muscle strips were immersed in organ baths maintained at $36.5^{\circ} \mathrm{C}$ with oxygenated Krebs-Ringer bicarbonate solution (KRB). KRB had the following composition (in mM): $120.4 \mathrm{NaCl}, 5.9 \mathrm{KCl}, 1.2 \mathrm{MgCl}_{2}, 15.5 \mathrm{NaHCO}_{3}, 1.2$ $\mathrm{NH}_{2} \mathrm{PO}_{4}, 11.5 \mathrm{D}$-glucose and $2.5 \mathrm{CaCl}_{2}$. The $\mathrm{pH}$ of $\mathrm{KRB}$ was 7.3-7.4 when bubbled with $97 \% \mathrm{O}_{2}-3 \% \mathrm{CO}_{2}$ at $36.5^{\circ} \mathrm{C}$.

The muscle strips were allowed to equilibrate in the organ baths for 60 minutes, during which time the baths were continuously perfused with oxygenated KRB. All experiments were performed with an optimal passive tension of $0.7 \mathrm{~g}$. Changes in tension of the strips were recorded onto a computer via an analog-to-digital board (Chart5-ADInstruments, Bella Vista, NSW, Australia). To measure actual peak amplitude, the baseline has been adjusted using Clampfit software (Molecular Devices, pClamp version 10, Sunnyvale, CA, USA). Electrical field stimulation (EFS) was performed at various frequencies $(1,5,10$ and $20 \mathrm{~Hz})$ and train durations (1, 5, 10 and 20 seconds) to select optimal condition for experiments by two platinum ring electrodes paced around each strip. Electrodes were connected to a GRASS S88 (GRASS Instruments, Quincy, Mass, USA) stimulator.

\section{Protocols}

We examined EFS-induced contractile responses. Peak (the highest value) and nadir (the lowest value) of both circular and longitudinal muscle strips were measured during the first $1 \mathrm{mi}-$ 


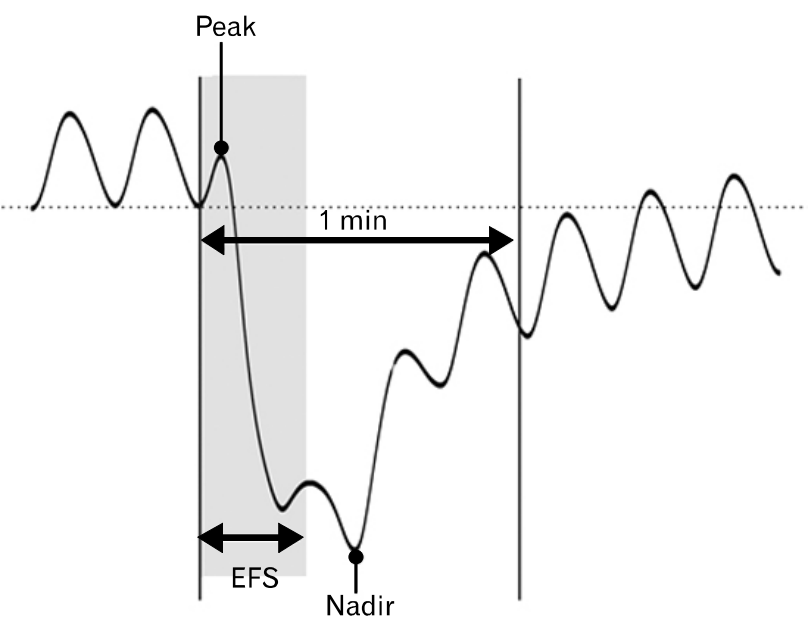

Figure 1. Peak and nadir represent the contractile response induced by electrical field stimulation (EFS). Peak is the highest value, while nadir stands for the lowest value during the first 1 minute after the initiation of EFS.

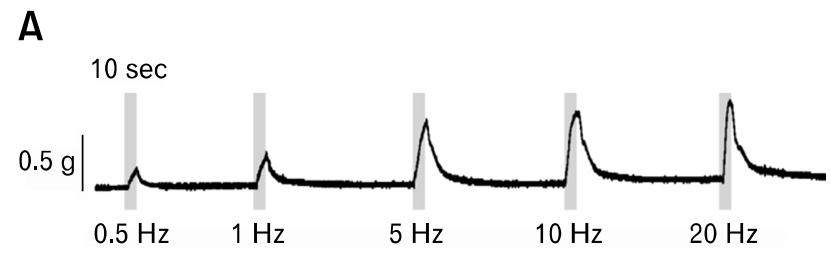

B

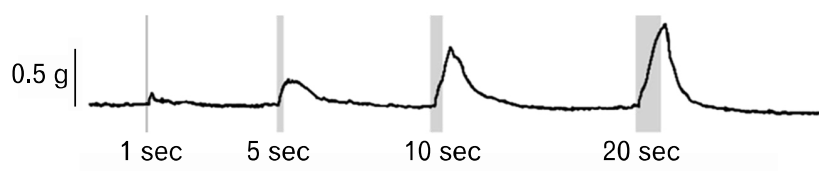

Figure 2. Effects of frequency and duration of electrical field stimulation (EFS) in the rat gastric fundus muscle strips. (1) EFS induced contraction in a frequency-dependent manner, (2) maximal tolerable contraction was found at 10 seconds of train duration of EFS.

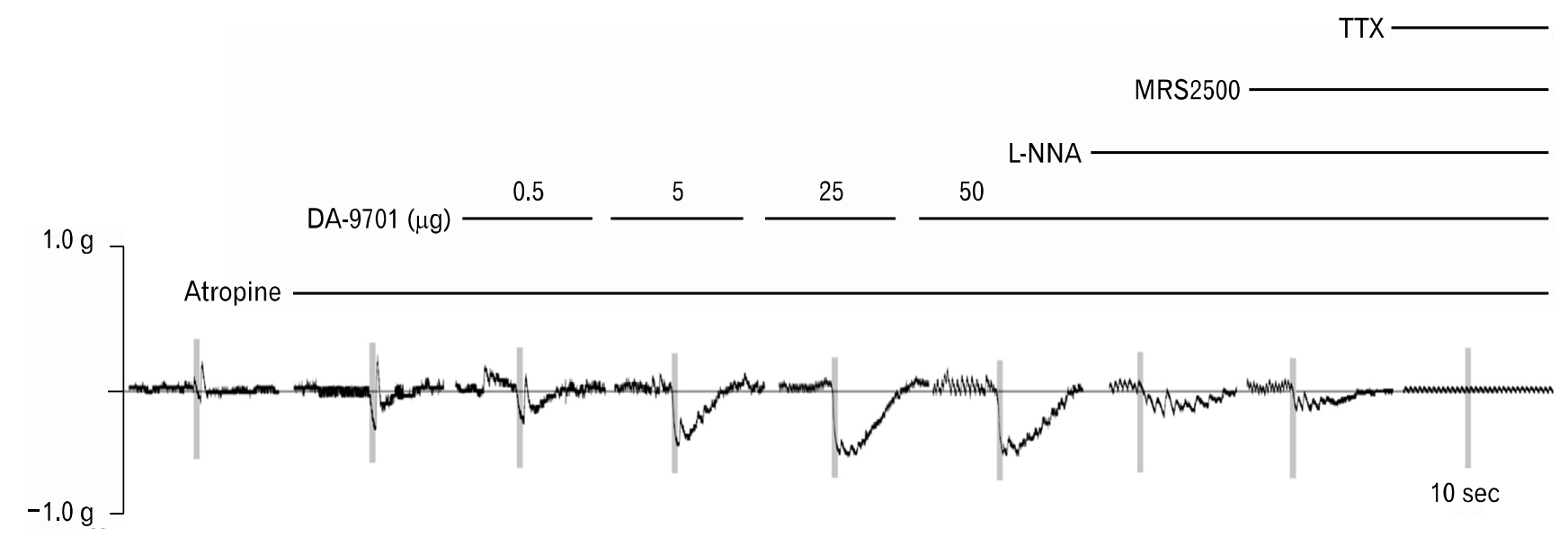

Figure 3. Typical traces of electrical field stimulation-induced contractile responses of the rat gastric fundus muscle strips after serial administration of atropine $(1 \mu \mathrm{M})$, DA-970 $(0.5,5,25$ and $50 \mu \mathrm{g})$, N-nitro-L-arginine (L-NNA, $100 \mu \mathrm{M})$, MRS2500 $(1 \mu \mathrm{M})$ and tetrodotoxin $(\mathrm{TTX}, 1 \mu \mathrm{M})$.

nute after the initiation of EFS (Fig. 1) in control state and after administration of atropine (a muscarinic antagonist, $1 \mu \mathrm{M}$ ), DA-970 $(0.5,5,25$ and $50 \mu \mathrm{g}), \mathrm{N}$-nitro-L-arginine (L-NNA, a NO synthase inhibitor, $100 \mu \mathrm{M}$ ) and MRS2500 (a purinergic P2Y1 antagonist, $1 \mu \mathrm{M}$ ), which were added in a sequential order to the organ bath. Then tetrodotoxin (TTX, $1 \mu \mathrm{M}$ ) was used to confirm that the responses of EFS were mediated via neural stimulation.

\section{Drugs and Solutions}

Atropine (Sigma Aldrich), MRS2500 (TOCRIS bioscience), L-NNA (Sigma Aldrich) and TTX (Alomone Labs) were used in this study. Atropine, MRS2500 and TTX were dissolved in distilled water, while L-NNA was dissolved in $1 \mathrm{M}$ hydrochloric acid. DA-9701 was kindly provided by Dong-A Pharmaceutical Co. Ltd. (Yongin, Korea) and was dissolved in KRB.

\section{Statistical Methods}

Statistical analyses were conducted using PASW Statistics 18 for Windows (SPSS, Inc., Chicago, IL, USA). Data are shown as mean \pm SE. Wilcoxon signed ranks test was used to evaluate changes of peak and nadir of EFS-induced contractile responses after sequential exposure to drugs. Kruskal Wallis test was used 
A

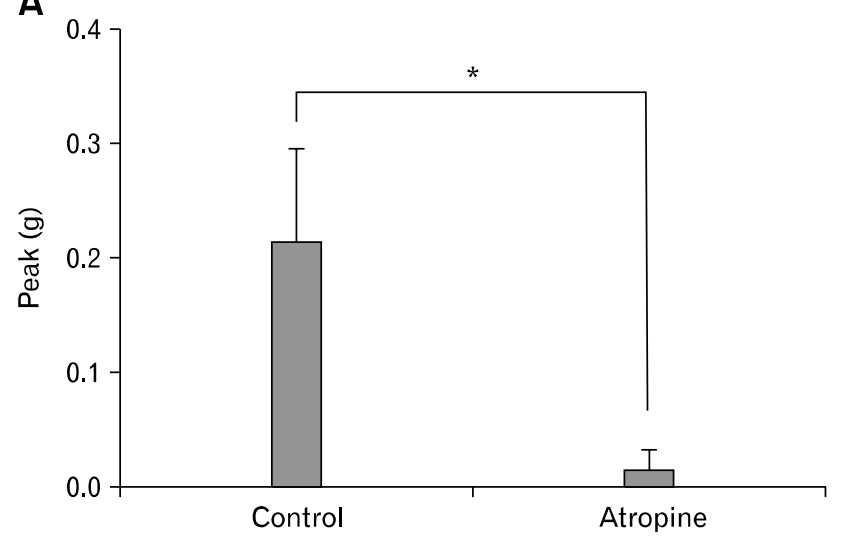

C

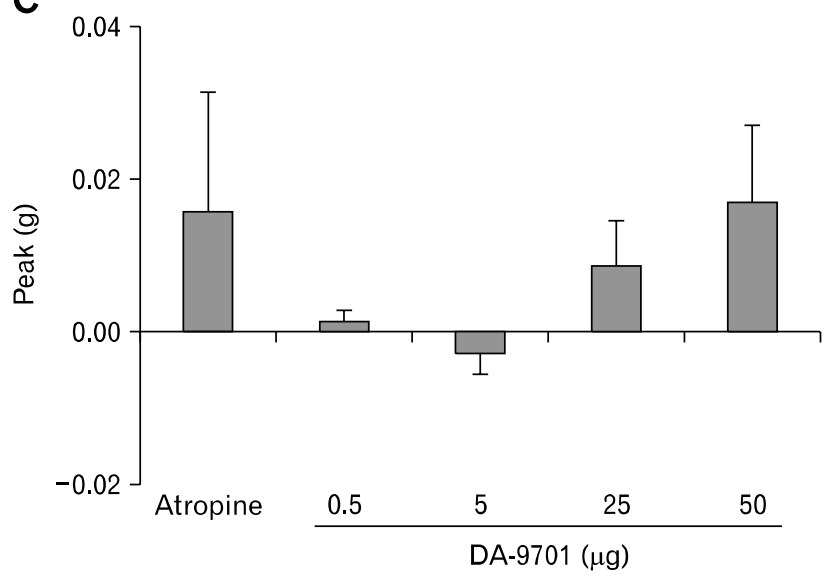

$\mathbf{E}$

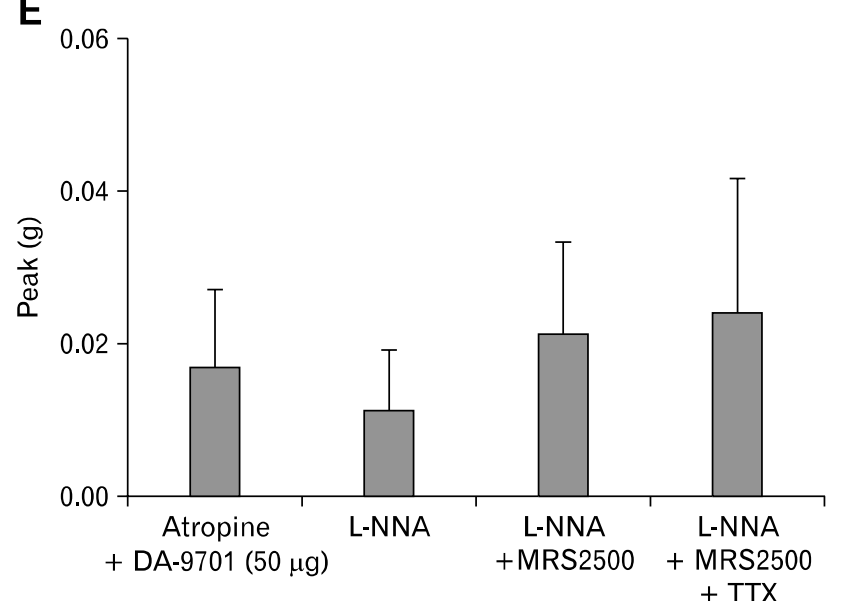

B

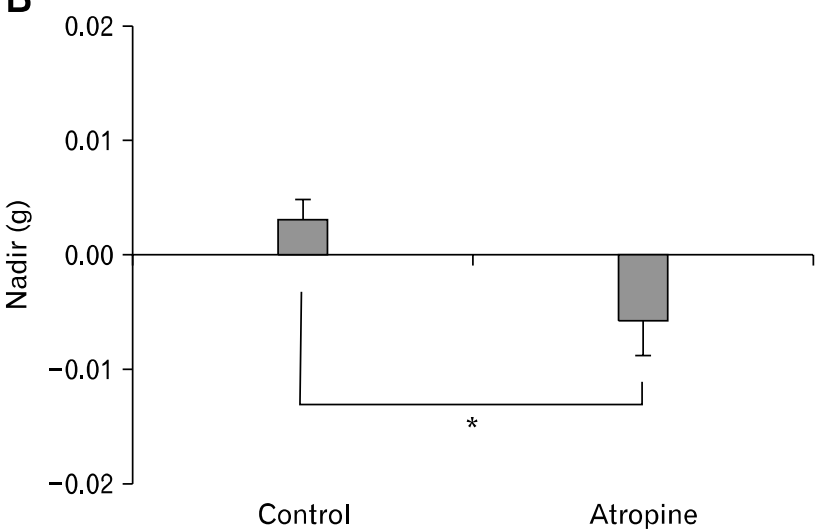

D

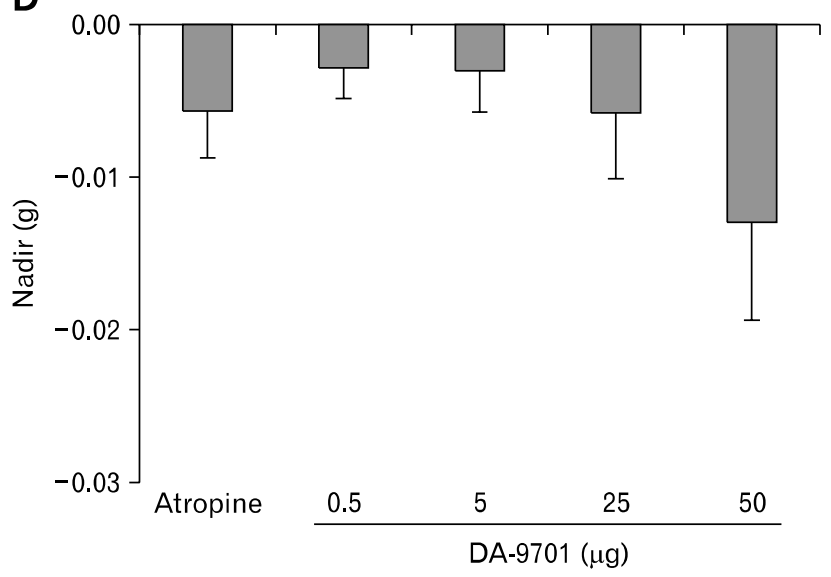

$\mathbf{F}$

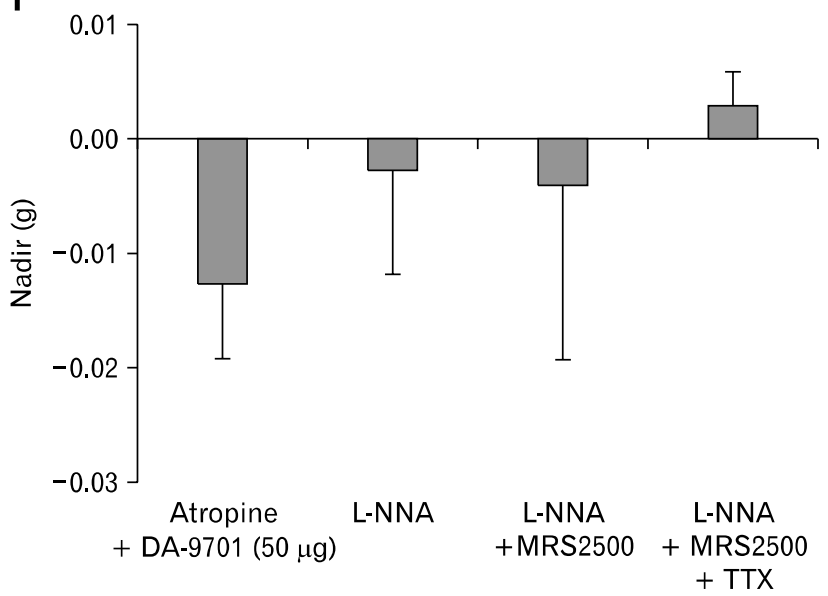

Figure 4. Electrical field stimulation (EFS)-induced response of the rat gastric fundus circular muscle strips after serial administration of atropine, DA-9701, N-nitro-L-arginine (L-NNA), MRS2500 and tetrodotoxin (TTX). (A, B) When atropine was added, peak was decreased and nadir was increased by inhibiting contraction $\left({ }^{*} P<0.05\right.$, by Wilcoxon signed ranks test). (C, D) When DA-9701 $(0.5,5,25$ and $50 \mu \mathrm{g})$ was added in the presence of atropine, peak and nadir did not show significant dose-dependent changes (Kruskal Wallis test for testing differences in EFS-induced contractile responses for different DA-9701 doses). (E, F) Subsequent addition of L-NNA, MRS2500 and TTX in the presence of atropine and DA-9701 $(50 \mu \mathrm{g})$ did not affect peak and nadir (compared with previous value by Wilcoxon signed ranks test). 
A

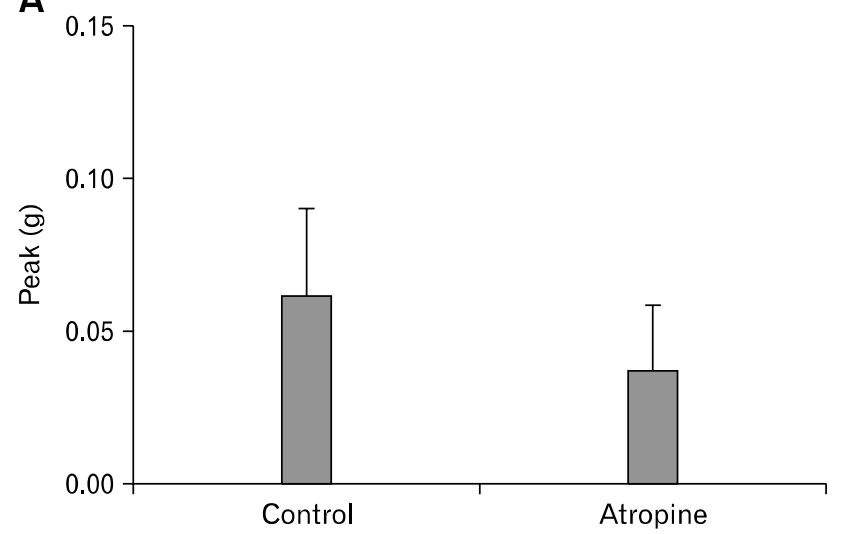

C

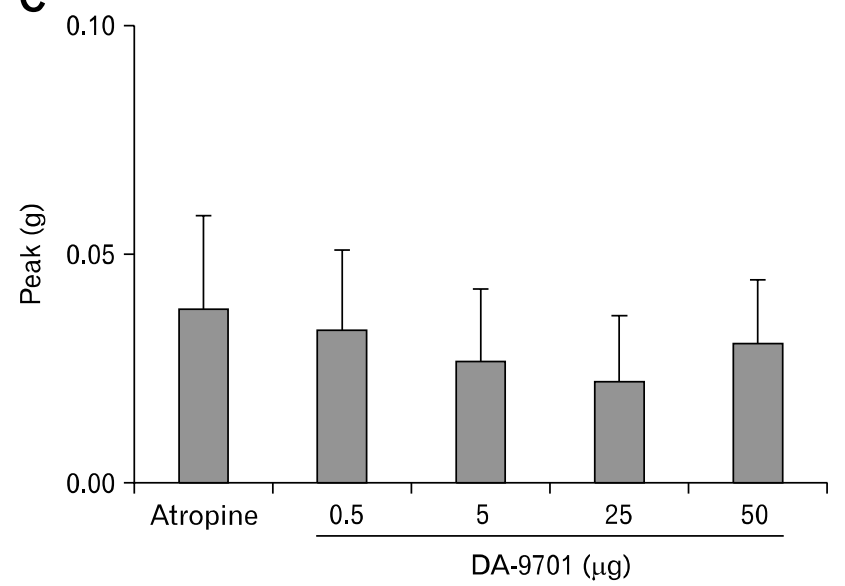

E

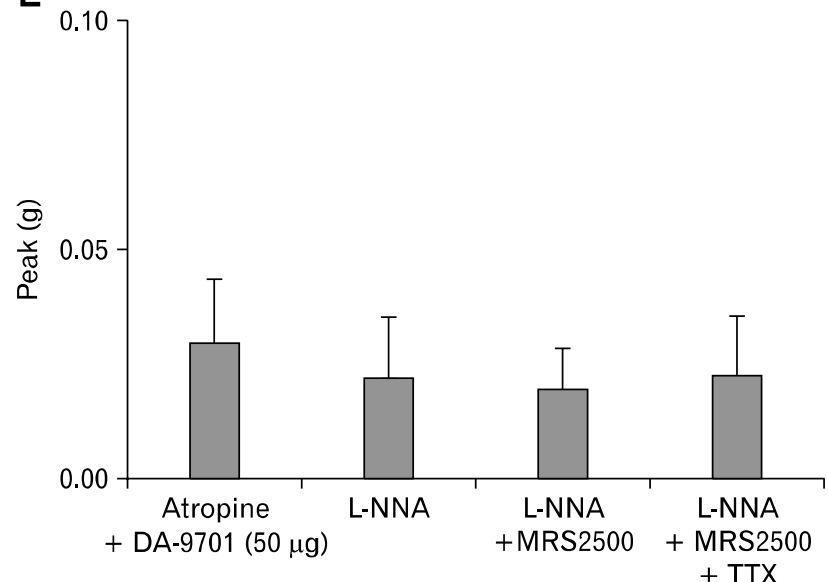

B

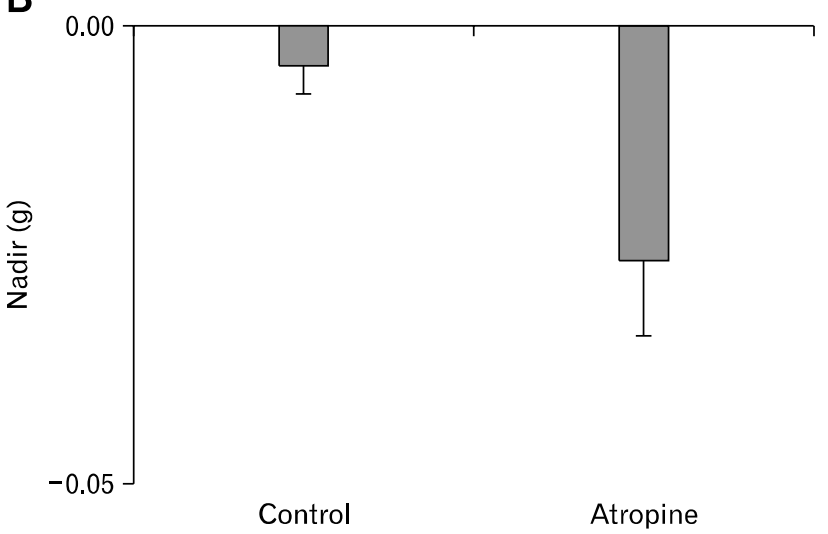

D

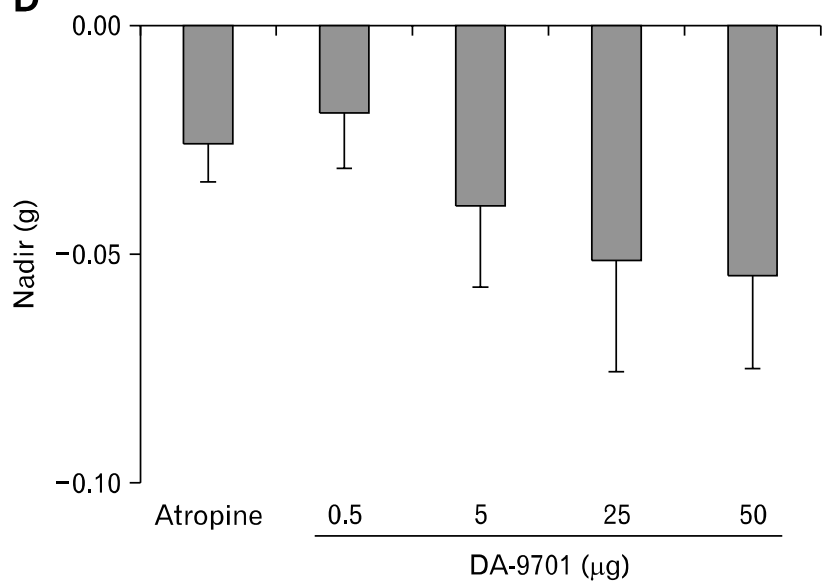

$\mathbf{F}$

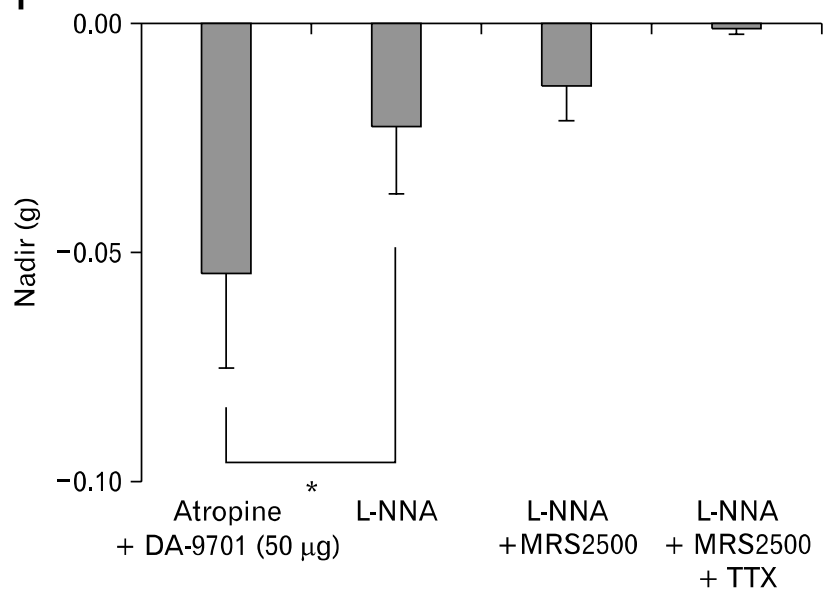

Figure 5. Electrical field stimulation-induced response of the rat gastric fundus longitudinal muscle strips after serial administration of atropine, DA-9701, N-nitro-L-arginine (L-NNA), MRS2500 and tetrodotoxin (TTX). (A, B) When atropine was added, peak and nadir did not show significant change (by Wilcoxon signed ranks test). (C, D) When DA-9701 (0.5, 5, 25 and $50 \mu \mathrm{g}$ ) was added in the presence of atropine, peak and nadir did not show significant dose-dependent change (Kruskal Wallis test for testing differences in EFS-induced contractile responses for different DA-9701 doses). (E) Subsequent addition of L-NNA, MRS2500 and TTX in the presence of atropine and DA-9701 (50 $\mu \mathrm{g})$ did not affect peak (compared with previous value by Wilcoxon signed ranks test). (F) Subsequent addition of L-NNA in the presence of atropine and DA-9701 (50 $\mu \mathrm{g}$ ) decreased nadir by inhibiting relaxation, while addition of MRS2500 and TTX in the presence of atropine, DA-9701 (50 $\mu \mathrm{g})$ and L-NNA did not affect nadir further $\left({ }^{*} P<0.05\right.$, compared with previous value by Wilcoxon signed ranks test). 
to test differences of peak and nadir of EFS-induced contractile responses for the different DA-9701 doses. A two-sided $P$-value $<0.05$ was considered as statistically significant.

\section{Results}

The optimal frequency and duration of EFS to evoke nerve-mediated relaxation in rat gastric fundus muscle was determined as $5 \mathrm{~Hz}$ for 10 seconds (Fig. 2). EFS-induced contractile response was found to be frequency and duration-dependent. However, the differences between 5 and $10 \mathrm{~Hz}$ and between 10 and 20 seconds were not significant.

Figure 3 shows typical traces in control state and of responses by sequential addition of atropine, DA-9701, L-NNA, MRS2500 and TTX to the organ bath under EFS.

\section{Electrical Field Stimulation-induced Responses in the Circular Muscle Strips}

Figure 4 shows EFS-induced contractile response of the rat gastric fundus circular muscle strips $(\mathrm{n}=7)$ after serial administration of atropine, DA-9701, L-NNA, MRS2500 and TTX. EFS induced contractions in the control state. When atropine (1 $\mu \mathrm{M})$ was added, peak was decreased by inhibiting contraction from $0.216 \pm 0.080 \mathrm{~g}$ to $0.016 \pm 0.016 \mathrm{~g}(P=0.043$; Fig. 4A). Addition of DA-9701 $(0.5,5,25$ and $50 \mu \mathrm{g})$ in the presence of atropine had no significant effect on peak from $0.016 \pm 0.016 \mathrm{~g}$ to $0.001 \pm 0.001 \mathrm{~g},-0.003 \pm 0.003 \mathrm{~g}, 0.009 \pm 0.006 \mathrm{~g}$ and $0.017 \pm 0.010 \mathrm{~g}$, respectively $(P=0.207$; Fig. $4 \mathrm{C})$. Subsequent addition of L-NNA $(100 \mu \mathrm{M}), \operatorname{MRS} 2500(1 \mu \mathrm{M})$ and TTX (1 $\mu \mathrm{M})$ in the presence of atropine and DA-9701 (50 $\mu \mathrm{g})$ did not affect peak from $0.017 \pm 0.010 \mathrm{~g}$ to $0.011 \pm 0.008 \mathrm{~g}(P=$ $0.180), 0.021 \pm 0.012 \mathrm{~g}(P=0.285)$ and $0.024 \pm 0.017 \mathrm{~g}(P=$ 1.000), respectively (Fig. 4E).

Atropine $(1 \mu \mathrm{M})$ increased nadir by inhibiting contraction from $0.003 \pm 0.002 \mathrm{~g}$ to $-0.006 \pm 0.003 \mathrm{~g}(P=0.034$; Fig. $4 \mathrm{~B})$. When DA-9701 $(0.5,5,25$ and $50 \mu \mathrm{g})$ was added in the presence of atropine, nadir increased in a dose-dependent manner from $-0.006 \pm 0.003 \mathrm{~g}$ to $-0.003 \pm 0.002 \mathrm{~g},-0.003 \pm 0.003 \mathrm{~g}$, $-0.006 \pm 0.004 \mathrm{~g}$ and $-0.013 \pm 0.006 \mathrm{~g}$, respectively but it was not statistically significant $(P=0.684$; Fig. 4D). Subsequent addition of L-NNA $(100 \mu \mathrm{M})$ and MRS2500 $(1 \mu \mathrm{M})$ in the presence of atropine and DA-9701 $(50 \mu \mathrm{g})$ did not affect nadir from $-0.013 \pm 0.006 \mathrm{~g}$ to $-0.003 \pm 0.009 \mathrm{~g}(P=$ $0.141)$ and $-0.004 \pm 0.015 \mathrm{~g}(P=0.713)$, respectively (Fig. $4 \mathrm{~F})$. However addition of TTX in the presence of atropine,
DA-9701 (50 $\mu \mathrm{g})$, L-NNA and MRS2500 completely abolished EFS-induced relaxation (nadir $=0.003 \pm 0.003$ g; Fig. 4F).

\section{Electrical Field Stimulation-induced Responses in the Longitudinal Muscle Strips}

Figure 5 shows EFS-induced contractile response of the rat gastric fundus longitudinal muscle strips $(\mathrm{n}=9)$ after serial administration of atropine, DA-9701, L-NNA, MRS2500 and TTX. EFS induced contractions in the control state. When atropine $(1 \mu \mathrm{M})$ was added, peak did not show significant change from $0.062 \pm 0.028 \mathrm{~g}$ to $0.038 \pm 0.020 \mathrm{~g}(P=0.079$; Fig. $5 \mathrm{~A})$. Addition of DA-9701 $(0.5,5,25$ and $50 \mu \mathrm{g})$ in the presence of atropine had no significant effect on peak from $0.038 \pm 0.020 \mathrm{~g}$ to $0.033 \pm 0.017 \mathrm{~g}, 0.027 \pm 0.015 \mathrm{~g}, 0.022 \pm 0.014 \mathrm{~g}$ and 0.030 \pm 0.014 g, respectively $(P=0.902$; Fig. $5 \mathrm{C})$. Sequential addition of L-NNA $(100 \mu \mathrm{M}), \operatorname{MRS} 2500(1 \mu \mathrm{M})$ and TTX (1 $\mu \mathrm{M})$ in the presence of atropine and DA-9701 $(50 \mu \mathrm{g})$ did not affect peak from $0.030 \pm 0.014 \mathrm{~g}$ to $0.022 \pm 0.014 \mathrm{~g}(P=$ $0.465), 0.020 \pm 0.009 \mathrm{~g}(P=0.932)$ and $0.023 \pm 0.013 \mathrm{~g}(P=$ 0.916), respectively (Fig. 5E).

Atropine $(1 \mu \mathrm{M})$ did not affect nadir significantly from $-0.004 \pm 0.003 \mathrm{~g}$ to $-0.026 \pm 0.008 \mathrm{~g}(P=0.067$; Fig. $5 \mathrm{~B})$. When DA-9701 $(0.5,5,25$ and $50 \mu \mathrm{g})$ was added in the presence of atropine, nadir was increased in a dose-dependent from -0.026 $\pm 0.008 \mathrm{~g}$ to $-0.019 \pm 0.012 \mathrm{~g},-0.039 \pm 0.018 \mathrm{~g},-0.051$ $\pm 0.024 \mathrm{~g}$ and $-0.054 \pm 0.021 \mathrm{~g}$, respectively but it was not statistically significant $(P=0.949$; Fig. 5D). Addition of L-NNA $(100 \mu \mathrm{M})$ in the presence of atropine and DA-9701 (50 $\mu \mathrm{g})$ decreased nadir by inhibiting relaxation from $-0.05 \pm 0.21$ $\mathrm{g}$ to $-0.02 \pm 0.01 \mathrm{~g}(P=0.026$; Fig. 5F). However, subsequent application of MRS2500 $(1 \mu \mathrm{M})$ in the presence of atropine, DA-9701 (50 $\mu \mathrm{g})$ and L-NNA did not affect nadir further from $-0.022 \pm 0.015 \mathrm{~g}$ to $-0.013 \pm 0.008 \mathrm{~g}(P=0.400$; Fig. $5 \mathrm{~F}$ ). Addition of TTX in the presence of atropine, DA-9701 (50 $\mu \mathrm{g}), \mathrm{L}-\mathrm{NNA}$ and MRS2500 completely abolished EFS-induced relaxation (nadir $=-0.001 \pm 0.001$ g; Fig. $5 \mathrm{~F}$ ).

\section{Discussion}

DA-9701 is a newly-formulated agent obtained from extracts of Pharbitis Semen and Corydalis Tuber and has strong prokinetic effects. In a recent study, DA-9701 increased gastric volume in a dose-dependent manner, and improved gastric accommodation by increasing the postprandial gastric volume. ${ }^{9}$ To examine how DA-9701 affects the muscle relaxation in the rat gas- 
tric fundus, L-NNA and MRS2500 were added to organ bath in a sequential order with EFS in the presence of atropine and DA-9701. Then TTX was used to confirm that the responses of EFS were mediated via neural stimulation. To exclude direct effect of DA-9701 on the gastric muscle, we checked spontaneous contraction at various concentrations $(5,10,50,100$ and $200 \mu \mathrm{g})$ of DA-9701 without EFS in the presence of TTX $(1 \mu \mathrm{M})$. According to the results, DA-9701 had a direct effect on the muscle when its concentration was over $50 \mu \mathrm{g}$ (data not shown). Therefore we did experiments with DA-9701 $(0.5,5,25$ and 50 $\mu \mathrm{g})$.

Non-adrenergic, non-cholinergic (NANC) nerves play an important role in the inhibition of gastrointestinal smooth muscle, being involved in many important physiological reflexes, including gastric receptive relaxation. ${ }^{12,13} \mathrm{NO}$ is considered the predominant inhibitory neurotransmitter in gastrointestinal smooth muscles. ${ }^{14,15}$ The purinergic neurotransmitter is inhibitory on gastrointestinal smooth muscles and has long been thought to be ATP. ${ }^{16}$ In fact, the purine neurotransmitter might be $\beta$-nicotinic adenine dinucleotide, because this nucleotide better fulfills the criteria for a neurotransmitter. ${ }^{17,18}$ In some regions of the gut, VIP and/or pituitary adenylate cyclase-activating polypeptide (PACAP) also contribute to inhibitory neurotransmission, but these substances are released generally at high stimulus frequencies of nerve stimulation $(\geq 10 \mathrm{~Hz}) \cdot{ }^{19,20}$ VIP and PACAP act through VPAC1/2 receptors coupled to $\mathrm{G}_{\mathrm{s} .}{ }^{21,22}$ Several animal studies have demonstrated that gastric accommodation in the fundus is a complex phenomenon induced by multiple neurotransmitters including NO, ATP and VIP. ${ }^{10,11}$ In the rat gastric fundus, there are evidences that NO and VIP are inhibitory neurotransmitters. ${ }^{23,24}$ ATP is also thought to be involved in NANC inhibitory neurotransmission in the rat gastric fundus. ${ }^{25,26}$

In the present study, EFS-induced non-cholinergic relaxation of the rat gastric fundus in the presence of DA -9701 remained unaffected by MRS2500 but was reduced by L-NNA and completely abolished by TTX in longitudinal muscle strips. Similar responses were also observed in circular muscle strips but did not reach statistical significance. These results suggest that nitrergic pathway is the major mechanism involved in relaxation of the rat gastric fundus by DA-9701. However, blocking cholinergic and nitrergic components led to an incomplete antagonism of response to EFS in the presence of DA-9701. Addition of TTX in the presence of atropine, DA-9701 (50 $\mu \mathrm{g})$, L-NNA and MRS2500 completely abolished EFS-induced relaxation, although it did not show statistical significance. Thus another com- ponent in the inhibitory effect of DA-9701 might exist. Accordingly, to determine the corresponding neurotransmitter in the inhibitory effect of DA-9701, further study with an appropriate sample number to investigate the change of relaxant response by antibody specific to each neurotransmitter and to perform immunohistochemistry experiments to demonstrate its expression in the rat gastric fundus smooth muscle is needed.

In conclusion, our data suggest that the inhibitory effect of DA-9701 on the rat gastric fundus relaxation is mainly mediated by nitrergic rather than purinergic pathway.

\section{References}

1. Talley NJ, Stanghellini V, Heading RC, Koch KL, Malagelada JR, Tytgat GN. Functional gastroduodenal disorders. Gut 1999; 45(suppl 2):II37-II42.

2. Tack J, Bisschops R, Sarnelli G. Pathophysiology and treatment of functional dyspepsia. Gastroenterology 2004;127:1239-1255.

3. Maes BD, Ghoos YF, Hiele MI, Rutgeerts PJ. Gastric emptying rate of solids in patients with nonulcer dyspepsia. Dig Dis Sci 1997;42:1158-1162.

4. Sarnelli G, Caenepeel P, Geypens B, Janssens J, Tack J. Symptoms associated with impaired gastric emptying of solids and liquids in functional dyspepsia. Am J Gastroenterol 2003;98:783-788.

5. Boeckxstaens GE, Hirsch DP, Kuiken SD, Heisterkamp SH, Tytgat GN. The proximal stomach and postprandial symptoms in functional dyspeptics. Am J Gastroenterol 2002;97:40-48.

6. van den Elzen BD, Boeckxstaens GE. Review article: a critical view on impaired accommodation as therapeutic target for functional dyspepsia. Aliment Pharmacol Ther 2006;23:1499-1510.

7. Lee TH, Choi JJ, Kim DH, et al. Gastroprokinetic effects of DA-9701, a new prokinetic agent formulated with Pharbitis Semen and Corydalis Tuber. Phytomedicine 2008;15:836-843.

8. Lee TH, Son M, Kim SY. Effects of corydaline from Corydalis tuber on gastric motor function in an animal model. Biol Pharm Bull 2010;33:958-962.

9. Kim ER, Min BH, Lee SO, Lee TH, Son M, Rhee PL. Effects of DA-9701, a novel prokinetic agent, on gastric accommodation in conscious dogs. J Gastroenterol Hepatol 2012;27:766-772.

10. Boeckxstaens GE, Pelckmans PA. Nitric oxide and the non-adrenergic non-cholinergic neurotransmission. Comp Biochem Physiol A Physiol 1997;118:925-937.

11. Lefebvre RA. Non-adrenergic non-cholinergic neurotransmission in the proximal stomach. Gen Pharmacol 1993;24:257-266.

12. Olsson C, Holmgren S. The control of gut motility. Comp Biochem Physiol A Mol Integr Physiol 2001;128:481-503.

13. Burnstock G. Physiology and pathophysiology of purinergic neurotransmission. Physiol Rev 2007;87:659-797.

14. Bult H, Boeckxstaens GE, Pelckmans PA, Jordaens FH, Van Maercke YM, Herman AG. Nitric oxide as an inhibitory non-adrenergic non-cholinergic neurotransmitter. Nature 1990;345:346-347.

15. Sanders KM, Ward SM. Nitric oxide as a mediator of nonadrenergic noncholinergic neurotransmission. Am J Physiol 1992;262(3 Pt 
1):G379-G392.

16. Burnstock G, Campbell G, Satchell D, Smythe A. Evidence that adenosine triphosphate or a related nucleotide is the transmitter substance released by non-adrenergic inhibitory nerves in the gut. $\mathrm{Br} \mathrm{J}$ Pharmacol 1970;40:668-688.

17. Mutafova-Yambolieva VN, Hwang SJ, Hao X, et al. Beta-nicotinamide adenine dinucleotide is an inhibitory neurotransmitter in visceral smooth muscle. Proc Natl Acad Sci USA 2007;104:1635916364.

18. Hwang SJ, Durnin L, Dwyer L, et al. $\beta$-nicotinamide adenine dinucleotide is an enteric inhibitory neurotransmitter in human and nonhuman primate colons. Gastroenterology 2011;140:608-617, e6.

19. Goyal RK, Rattan S, Said SI. VIP as a possible neurotransmitter of non-cholinergic non-adrenergic inhibitory neurones. Nature 1980; 288:378-380.

20. McConalogue K, Furness JB, Vremec MA, Holst JJ, Tornøe K, Marley PD. Histochemical, pharmacological, biochemical and chromatographic evidence that pituitary adenylyl cyclase activating peptide is involved in inhibitory neurotransmission in the taenia of the guinea-pig caecum. J Auton Nerv Syst 1995;50:311-322.

21. Hagen BM, Bayguinov O, Sanders KM. VIP and PACAP regulate localized $\mathrm{Ca}^{2+}$ transients via cAMP-dependent mechanism. Am J Physiol Cell Physiol 2006;291:C375-C385.

22. Schulz S, Röcken C, Mawrin C, Weise W, Höllt V, Schulz S. Immunocytochemical identification of VPAC1, VPAC2, and PAC1 receptors in normal and neoplastic human tissues with subtype-specific antibodies. Clin Cancer Res 2004;10:8235-8242.

23. Li CG, Rand MJ. Nitric oxide and vasoactive intestinal polypeptide mediate non-adrenergic, non-cholinergic inhibitory transmission to smooth muscle of the rat gastric fundus. Eur J Pharmacol 1990; 191:303-309.

24. Boeckxstaens GE, Pelckmans PA, De Man JG, Bult H, Herman AG, Van Maercke YM. Evidence for a differential release of nitric oxide and vasoactive intestinal polypeptide by nonadrenergic noncholinergic nerves in the rat gastric fundus. Arch Int Pharmacodyn Ther 1992;318:107-115.

25. Belai A, Lefebvre RA, Burnstock G. Motor activity and neurotransmitter release in the gastric fundus of streptozotocin-diabetic rats. Eur J Pharmacol 1991;194:225-234.

26. Vetri T, Bonvissuto F, Marino A, Postorino A. Nitrergic and purinergic interplay in inhibitory transmission in rat gastric fundus. Auton Autacoid Pharmacol 2007;27:151-157. 